\title{
BREVE RELATO DE UN BESTIARIO EN MIL MESETAS
}

\section{BRIEF ACCOUNT OF A BESTIARY IN A THOUSAND PLATEAUS}

Olga del Pilar López ${ }^{1}$

\begin{abstract}
Resumen: Este artículo busca pensar el animal vinculado a la filosofía, o bien una filosofía animal. Si bien este enfoque está al orden del día en los debates contemporáneos, nuestro interés es pensarlo particularmente en la obra de Gilles Deleuze y Félix Guattari quienes siguen a los animales para desembarazarse de los conceptos que han acompañado a la filosofía occidental logocentrista, a la vez que inventan nuevos conceptos vehiculados por los animales. Es en ese sentido que ellos reconocen la responsabilidad frente a los animales y los nuevos ritornelos filosóficos que estos les permitirán elaborar.
\end{abstract}

Palabras-clave: Filosofía deleuzo-guattariana; animales; devenires; arte.

\begin{abstract}
This article seeks to think about the animal linked to philosophy, or an animal philosophy. Although this approach is the order of the day in contemporary debates, our interest is to think particularly about the work of Gilles Deleuze and Félix Guattari who follow the animals to get rid of the concepts that have accompanied the western logocentric philosophy, and at the same time they invent new concepts conveyed by animals. It is in this sense that they recognize the responsibility towards the animals and the new philosophical ritornellos that these will allow them to elaborate.
\end{abstract}

Keywords: Deleuze and Guattari's Philosophy; animals; becomings; art.

Si la Garrapata, el Lobo, el Caballo, etc., son verdaderos nombres propios, no es en razón de los denominadores genéricos y específicos que los caracterizan, sino de las velocidades que los componen y de los afectos que los satisfacen: el acontecimiento que ellos son por ellos mismos y en los agenciamientos, devenir-caballo del pequeño Hans, devenir-lobo del Salvaje, devenir-garrapata de los Estoicos (otros nombres propios). Deleuze, Guattari, Mil Mesetas, p. 267

\section{Introducción}

En las últimas tendencias de la filosofía contemporánea encontramos una filosofía vegetal y una filosofía animal. Es decir, estaríamos en el polo opuesto de un hegelianismo que tiene entre sus pilares la diferencia entre el espíritu y los animales, pues consideraba a estos como seres inferiores incomparables al hombre. Es en ese sentido que la dialéctica del amo y el esclavo tiene entre sus objetivos demostrar que uno no es un animal y que más bien ha superado ese estado al sacrificarse por otro. Bajo diferentes ángulos Hegel considera la naturaleza como un estado despreciable del cual debemos tomar distancia. Igualmente, Heidegger señala esta separación, para lo cual retoma el témino Umwelt (mundo circundante) de Uexküll, pero para hacer una lectura completamente

\footnotetext{
1 Ph.D. en Estética. Profesora titular de la Unidad de Transversal, Universidad de las Artes. E-mail: olga.lopez@uartes.edu.ec.
} 
distinta a la conocida de Deleuze y Guattari, es decir, afirmar que el animal se encuentra aturdido en su pobreza y ajeno al mundo. Éste actuaría únicamente en los anillos desinhibidores que desatan su comportamiento. Ahora bien, el giro de la filosofía contemporánea descentra el problema del pensamiento y pone el énfasis en el campo de relaciones en el cual se constituyen los animales y los vegetales, de los cuales surgirían modos de existencia. Este anti-humanismo presente en la filosofía contemporánea permite incluir otras miradas, otros puntos de vista animales, vegetales o minerales. Entre los autores que permitieron esta línea de fuga, esta desterritorialización de la tradición occidental debemos contar a Jacques Derrida quien señala el logocentrismo que ha acompañado a la filosofía occidental:

Por ejemplo Descartes, Kant, Heidegger, Lacan y Lévinas. Sus discursos son sólidos y profundos pero, en estos discursos, todo sucede como si aquéllos no hubieran sido nunca mirados, y sobre todo desnudos, por un animal que se hubiera dirigido a ellos. Todo sucede, al menos, como si esta experiencia turbadora, suponiendo que les haya ocurrido, no hubiese sido teóricamente grabada, precisamente allí donde convertían al animal en un teorema, una cosa vista y no vidente. La experiencia del animal que ve, del animal que los mira, no la han tenido en cuenta en la arquitectura teórica o filosófica de sus discursos. La han negado, en resumidas cuentas, tanto como la han desconocido. (DERRIDA, 2008, p. 29-30)

La mirada del animal que desnuda al filósofo Derrida nos recuerda uno de los ejes válidos de la fenomenología de Merleau-Ponty: la mirada de las cosas y el sentir del mundo. Y si bien este filósofo no habla de los animales, deja, sin embargo, abierta una posibilidad cuando propone un mundo activo que nos mira, de allí el afán del artista de devolver esa mirada, de tornarla materia del arte. Por ello, en esto que indica Derrida encontramos un sentir que forma parte hoy de una filosofía animal que indaga, acompañada de la etología, por el sentir animal y reconoce esas diversas maneras de ver que tienen las distintas especies que, si bien no son frontales -salvo en situaciones bien particulares-, están atentas al mundo. (MARCELLI, 2009).

Este retorno filosófico al animal está inscrito en los movimientos ecológicos de nuestros días, en la crisis climática, así como en una nueva pregunta sobre nuestros hábitos alimenticios en un mundo con casi siete mil millones de personas donde en su gran mayoría sólo se reconoce al animal como una fuente de biomasa, desconociendo toda su existencia en tanto que ser sintiente. La producción industrial de la vida en función del mercado lleva a la filosofía a preguntarse por ese "Otro" que ha estado entre nosotros de diversas maneras: doméstico, salvaje o en tanto que alimento, para desglosar sus pliegues, para sentir su mirada, su relación con el aprendizaje, con el mimetismo, con lo colectivo. Por ello, si los filósofos modernos indicados previamente en la cita de Derrida son insensibles al animal -aspecto fuertemente presente en las religiones monoteístas-, y lo vislumbran como una máquina como bien es el caso de Malebranche, quien golpeaba a su perro, para luego juzgar sus ladridos de este modo: "Mira, es exactamente como un reloj que suena puntual'(CHAPOUTHIER, 2009), la filosofía contemporánea lo reconoce como un hermano al que debe mirar a la cara, no tanto para sentir la propia satisfacción de la condición humana, sino para reconocer un conjunto de aspectos que nos vinculan: la experiencia de la muerte, la técnica, el sentimiento de dolor e incluso la producción de arte. Sin embargo, según Daniel Marcelli habría una diferencia entre los animales y nosotros: un control proto-imperativo propio de los animales, sobre todo en los primates y un control proto-declarativo propio de los humanos. Esto implica que, si bien hay una imitación en los primeros, en general los animales no se miran directamente, salvo si van a cazar o incluso en situaciones de copulación. El control proto-imperativo significa que la relación entre una 
madre y su cría, caso específico entre los chimpancés, no se concentra sobre un intercambio de miradas, sino en una mirada desviada, que no por ello es menos fuerte y concentrada, pues la madre está atenta a lo que hace su cría. Esta relación busca enseñar por imitación, pero sin implicar una concentración sobre los rostros. En cambio, en los segundos, los humanos, existe un juego de miradas entre un objeto deseado, el bebé y la madre, quien a continuación pronuncia el nombre del objeto que el bebé desea para activar este vínculo directo de miradas, esto sería, según el autor del artículo citado un acto proto-declarativo exclusivo de los humanos. Ahora bien, esta diferencia no busca volver al diseño inteligente propio del siglo XIX, sino pensar los procesos de investigación en cada caso. Esto en cuanto a lo que tiene que ver con nuestra relación con el mundo y con los otros, más no en la posibilidad del sentir, presente en todos los seres vivos. Bajo esta óptica el animal deja de estar encerrado en su propia carne y, a merced de la voluntad humana, para más bien sentirlo como el borde intensivo con el cual compartimos un destino común, pues está siendo afectado y maltratado, por este mismo sistema que no sólo destruye el planeta, sino que ha perdido toda consideración por la vida en todas sus formas.

\section{Los animales que ayudaron a pensar a Deleuze y Guattari}

Deleuze y Guattari propagan la animalidad a través de los flujos de su pensamiento, como un contagio, como una epidemia, al punto que cuando nos aproximarnos a sus rizomas nos encontramos en diversos momentos con esta animalidad desbordada que permite no sólo escapar a una tradición filosófica, sino entablar una ética y una estética. Para comenzar, recordemos la conversación de Gilles Deleuze con Claire Parnet en el Abecedario ${ }^{2}$ donde él comienza a construir un alfabeto de manera ordenada y, por supuesto, la primera letra es la A, letra con la cual se aproxima al animal. En este diálogo él aclara tres aspectos. En primer lugar, no le interesan los animales domésticos, tipo el perro o el gato, los cuales terminan inscritos en una estructura familiar edipizada. En segundo lugar: al inscribir a los animales domésticos en esta estructura, ellos terminan por ser humanizados lo cual conlleva una relación humana con el animal. En tercer lugar, él sugiere una tercera alternativa: entablar una relación animal con el animal. Ahora bien, consideramos que esta es la alternativa que atraviesa su obra y que como lo diría Anne Sauvagnargues en Del animal al arte, (SAUVAGNARGUES, 2006) es a través de la etología que Deleuze logra escapar a la representación, a lo cual debemos agregar: la significación, la subjetividad y la interpretación. En este diálogo entre Parnet y Deleuze ellos se deslizan hacia el devenir animal del escritor, lo cual nos lleva a una especie de distinción que no siempre es estricta: el devenir-animal estaría más en vínculo con los escritores, mientras que el devenir imperceptible estaría más en relación con la pintura. Así, tanto el animal, como el devenir-animal del escritor con los que abre el Abecedario ponen en evidencia uno de los ejes del pensamiento de Deleuze y Guattari: el animal moviliza su pensamiento, permite generar todo tipo de encuentros, hibridaciones y deshumanizaciones que quizá nos lleve a decir que su filosofía no fue escrita para nosotros, sino para los animales y, en esa medida Deleuze y Guattari encarnan esa responsabilidad que tenemos frente a ellos. Por eso, el animal no es el otro, sino el borde intensivo de lo humano o bien la manera como éste se pone en contacto con la materia e incluso con lo inorgánico.

Así, nuestra tesis es: cada que Deleuze y Guattari citan un animal, en relación, en devenir, en metamorfosis, esto está ligado a un concepto. De modo que ellos estarían movilizados por los animales que aparecen en su filosofía, la cual termina por ser un bestiario, que no sólo los vincula con unos filósofos minoritarios, sino que tiene la intención de hacer de su propia filosofía algo minoritario, es por ello que, como decía antes, ésta quizás sienta y asuma esa responsabilidad directa

\footnotetext{
${ }^{2}$ L'abécédaire es un programa televisivo producido por Pierre-André Boutang entre 1988-1989 y transmitido en 1996 a título de post mortem auctoris.
} 
con los animales. Para desglozar esta relación entre los conceptos deleuzo-guattarianos y los animales recordemos el siguiente fragmento de Anne Sauvagnargues:

En cada caso, un personaje animal sirve de soporte al análisis y de agente de transformación conceptual: los chillidos y silbidos de la rata Josefina en Kafka, las avispas y las orquídeas de Proust, las garrapatas de Uexküll o el pez chino, el pinzón de Australia, pasan a ser personajes conceptuales, singularidades notables, interlocutores para la filosofía.

(SAUVAGNARGUES, 2006, p. 12-13).

En estos ejemplos que cita Sauvagnargues vemos la presencia del arte y cómo a través de una relación animal con el animal, los escritores de esta cita llevan a cabo devenires animales que los conducen a devenires minoritarios, pues su escritura sale del canon que prevalecía en la literatura de su época. En otros términos, nos obliga a perder nuestra propia humanidad para acceder a las moléculas animales que se propagan a través de la escritura. Es en ese sentido, que Deleuze y Guattari no sólo viven un proceso de deshumanización, sino de molecularización con diversos devenires según los animales que citen. Así, no sólo sería el arte, sino también la filosofía que nos tornaría sensibles a estas moléculas animales, a partir de una alianza de la cual no sólo los filósofos salen transformados, sino también el animal, lo cual se hace evidente con nuestra lectura, ya que luego de leer a Deleuze y Guattari no miramos ni nos relacionamos con los animales de la misma manera, sabemos que su contacto, que su mirada nos afecta y nos transforma. Veamos, entonces en este bestiario cómo los animales son la alianza que permite a nuestros pensadores escapar a la filosofía occidental y crear nuevos conceptos. Esto lo mostraremos a partir de un esquema que extrae algunos flujos de la obra deleuzo-guattariana.

En primer lugar, Gilbert Simondon contribuye a esta relación con el animal, pues Deleuze y Guattari retoman términos como metaestabilidad en tanto que diferencia de potencial que induce un cambio de fase, así como el término de modulación que escapa a la idea de forma para, más bien, pensar las interacciones de fuerzas y materiales. Por tanto, en términos simondonianos: “...el ser no posee una unidad de identidad, que es la del estado estable en el cual ninguna transformación es posible; el ser posee una unidad transductiva; es decir que puede desfasarse en relación consigo mismo, desbordarse él mismo de un lado y otro de su centro" (SIMONDON, 2015, p. 19-20). En ese sentido, la individuación es aquello que no cesa de cambiar de naturaleza. Lo cual en la red de tela de araña que van elaborando Deleuze y Guattari tiene resonancias espinosistas y hace que quizás sea Spinoza el que guie estas elecciones tanto por su relación anti jerárquica de la naturaleza, por su vínculo con la animalidad, así como por ese devenir-niño que detectan en él nuestros autores.

Igualmente, Deleuze y Guattari elaboran una relación con el animal que escapa a las clasificaciones binarias y a la supremacía del humano, a través de Geoffroy Saint-Hilaire. Deleuze y Guattari citan el debate del siglo XIX entre Cuvier y Geoffroy en el cual, el primero retoma una línea aristotélica y esencialista del animal a partir de la cual constituye series que distinguen claramente entre unos y otros animales. (DELEUZE y GUATTARI, 1980). Por su parte Geoffroy tomará una línea distinta, al demostrar que los seres son plegamientos diversos de la materia, pero que en realidad habría correspondencia entre ellos. Es en ese sentido que él propone el concepto de animal abstracto: un animal del cual provendrían todos, sin embargo esto no quiere decir que se anula la diferencia, sino que se reconoce el trabajo de la carne (la variación continua de un mismo plano), a través de lo cual se destituye toda jerarquía de los seres para pensarlos en un plano horizontal donde una hormiga, un perro, un puma o un humano son iguales, sólo con moldeamientos que los diferencian (conexiones diversas de sus partes). En Geoffroy, a su vez, sentimos aires espinosistas, que nos hacen entender la afinidad de 
Deleuze y Guattari con su perspectiva. Ellos se siguen acompañando por etólogos como Rémy Chauvin, Samuel Butler, Jacob von Uexküll, entre otros, que les ayudan a realizar su propia metamorfosis e ir constituyendo esa multiplicidad de devenires que los van afectando.

Sin embargo, es ya con Geoffroy Saint-Hilaire que Deleuze y Guattari van a entender y a participar de una involución, puesto que con este teórico se ponen en contacto con las larvas, los embriones, los huevos de todo tipo, allí donde no existe organización alguna y donde se hace posible pensar un cuerpo sin órganos, ejemplo de ello es la reflexión de Geoffroy sobre los monstruos que cuestiona todo tipo de organización. La entrada de una involución interpela toda clasificación entre género y especie y nos pone en contacto con lo inorgánico: esas fuerzas que no cesan de modular y que están presentes en todo tipo de materia.

En segundo lugar, el animal permite a nuestros autores escapar al binomio de lo uno y lo múltiple, que sigue conservando su halo trascendente, para elaborar el concepto de multiplicidad. Aquí, ellos convocan todo tipo de manadas: lobos, vampiros, ratas, hormigas, abejas, elefantes, bacterias. Que pasan sus potencias de las unas a las otras, que entablan relaciones de contagio, de contaminación y disuelven toda clasificación. Esto lo vinculo con otro aspecto clave de este bestiario: la disolución de la rostrocidad. Pues justamente el rostro es el lugar de la identidad que sirve como dispositivo de humanización de plantas, animales o incluso minerales: los humanos imponen su rostrocidad. Sin embargo, las manadas permiten esta disolución de lo uno-identitario y más bien agencian el conjunto de relaciones de los cuerpos. Entablar esta relación animal con el animal permite encontrar las cabezas y, si bien las manadas convocan la indiscernabilidad de los rostros, esto también lo encuentra Deleuze en la pintura de Bacon quien se dedica al borramiento de los rostros humanos, pues:

No es que ella [la cabeza] carezca de espíritu, sino que es un espíritu que es cuerpo, soplo corporal y vital, un espíritu animal, es el espíritu animal del hombre: un espíritu-cerdo, un espíritu-búfalo, un espíritu-Perro, un espíritumurciélago... Es entonces un proyecto bien especial que persigue Bacon en tanto que retratista: deshacer el rostro, reencontrar o hacer surgir la cabeza bajo el rostro (DELEUZE, 2002, p. 27).

Vemos surgir en las pinturas de Bacon cabezas de pájaros, de toros que se fusionan con los rostros humanos, pero, sobre todo, la imposibilidad de cualquier reconocimiento y, más buen las fuerzas de esas cabezas que ponen en evidencia la Figura (deformación de la forma) y la intensidad de la carne que emana de los cuadros de Bacon.

En tercer lugar, es a través del animal que Deleuze y Guattari escapan al psicoanálisis, al reconocer tanto en los pacientes tratados por Guattari como en las descripciones clínicas de los psicoanalistas, no tanto una re-edipización del animal, sino distintos agenciamientos colectivos en los cuales aparecerían estos animales. Esa es una de las grandes acusaciones al psicoanálisis: descuidar el devenir-animal por intentar encerrar estas alianzas en arquetipos universalistas. Recuperar los animales negados del psicoanálisis como el caballo de Richard (paciente de Melanie Klein) y entender en que campo de relaciones se inscribe: la calle, el campo, otros animales. Y cómo Richard intercambia moléculas con este animal. Aquí se podría insistir en un aspecto clave del devenir-animal: el "entre", donde se generan los intercambios entre especies habitualmente separadas, como la orquídea y la avispa (descripción de la sexualidad en Sodoma y Gomorra de Marcel Proust) o bien Richard y su caballo. Lo anterior nos lleva a recordar el artículo de François Zourabichvilli quien insiste en el carácter literal del pensamiento Deleuzo-guattariano (ZOURABICHVILLI, 2011). Por tanto, este inter-especie que transforma a aquellos que participan del encuentro, no es tanto en un orden metafórico, sino 
en su condición metamórfica. Es entonces el concepto de metamorfosis que desplaza cualquier visión fantástica, imaginaria, simbólica o metafórica del devenir animal.

En cuarto lugar, Deleuze y Guattari escapan a una forma rígida y cerrada de individuación, ligada como veíamos antes al pensamiento de Gilbert Simondon, para más bien entenderla en tanto que acontecimiento: "una nube de langostas traída por el viento, a las cinco de la tarde; un vampiro que sale en la noche, hombre-lobo que sale con la luna". (DELEUZ y GATTARI, 1980, p. 321). La manada de langostas, el nivel del viento y la hora precisa del día constituyen entre ellos una individualidad, es decir, una hecceidad, la cual se pueden medir en términos de velocidad y de lentitud entre las partículas, lo cual implica que la invasión de langostas de las diez de la mañana sea distinta a esta de las cinco de la tarde: luz, movimiento, condiciones del terreno generan este acontecimiento único, esta individualidad. Esto hace igualmente posible que Deleuze y Guattari se desembaracen de la idea del ser, pues como Funes el memorioso de Borges, el perro de la mañana no es el mismo de media hora después y así a lo largo del día. El perro mismo es un acontecimiento y genera nuevos acontecimientos, hecceidades, según las alianzas que vaya entablando. Así, en el lugar de los seres, ellos ponen un devenir de acontecimientos. Lo cual nos remite de nuevo al pensamiento espinosista puesto que a partir de ahora es posible constituir cartografías de los cuerpos, es decir, según sus grados de potencia. Una cartografía se constituye, por tanto, de latitud: afectos de los cuales son capaces los cuerpos y de longitud: sus partes extensivas que se ponen en relación con estos afectos. Es quizás a esto que corresponda una geometría espinosista que a su vez nos remite a una etología de los afectos. Por tanto, si quisiéramos definir los distintos animales más que pasar por cualquier clasificación, nos remitiríamos a los afectos que poseen.

Esto nos lleva a nuestro quinto y último punto: si bien podemos pensar los animales según los afectos que portan los cuerpos y los agenciamientos que elaboran con estos, esto es insuficiente para pensar el arte. Así, no todos los animales producen arte, sino sólo aquellos que agencian un territorio. Con este gesto filosófico Deleuze y Guattari pasan del hábito al hábitat y es con este último que reconfiguran el concepto de arte que busca alejarse de la fenomenología, la cual centró toda la reflexión del arte en un cuerpo que siente. De nuevo los animales, en este caso con territorio, le permiten a Deleuze y Guattari tanto deshumanizar el arte como escapar a la fenomenología y su lugar privilegiado del cuerpo, que, según su filosofía, resulta demasiado blando para soportar las rasgaduras, las deformaciones, los gritos, las avalanchas que implican la producción artística. Por ello, la alternativa es el plano de composición, el territorio sobre el cual algunos animales despliegan materia expresiva, así como lo hace el Land art o la performance. Con los animales y sus ritornelos el arte sale metamorfoseado de la filosofía deleuzo-guattariana.

Por tanto, Deleuze hará de nuevo homenaje en Diálogos a los animales cuando agrega: "la araña y su tela, el piojo y el cráneo, la garrapata y un segmento de piel de mamífero: he aquí bestias filosóficas y no el pájaro de Minerva" (PARNET y DELEUZE, 1977, p. 75). Esta es pues una filosofía que se ha acompañado de los animales para transformar el pensamiento y quizás para indicarnos que es a los animales a quien debemos escuchar, que son ellos los que poseen toda la riqueza del mundo, lo cual nos lleva a poner un poco en suspenso nuestro parloteo humanista para poder escuchar esta "melodía de la naturaleza": los bajidos, los aullidos, los chillidos, los zumbidos que resuenan en la obra de Deleuze y Guattari y en particular en Mil Mesetas. Así como para ver y sentir los trazos, las líneas, los flujos de olores, las velocidades y las lentitudes con que construyen los animales sus ritornelos, con los que restauran infatigablemente sus territorios. De modo que, si como dice Julieta Yelin estaríamos lejos de la posibilidad de una biografía del animal, por lo cual el animal no tiene quien le escriba, sin embargo, nosotros encontramos en estas aproximaciones de Deleuze y Guattari una suerte 
de zoosophia que, en vez de tratar de escribir biografías de los animales con palabras, las constituye a través de sus trayectos territoriales, de sus composiciones colectivas, o bien de las fuerzas e intensidades que atraviesan los cuerpos. Entonces, quizás esta sea la manera como el animal escribe con su cuerpo y sobre la tierra sin necesidad de algo tan reducido como una hoja de papel: la biografía animal es una escritura de y en la tierra.

\section{Referencias}

CHAPOUTHIER, Georges. Le statut philosophique de l'animal: ni homme, ni objet. Le carnet Psy, 2009/8, n. 139, p. 23-25. <https://www.cairn.info/revue-le-carnet-psy-2009-8-page-23.htm>.

DELEUZE, Gilles; GUATTARI, Félix. Mille Plateaux. Paris: Minuit, 1980.

DELEUZE, Gilles. Francis Bacon, logique de la sensation. Paris: Seuil, 2002.

DERRIDA, Jacques. El animal que luego estoy si[gui]endo. Traducción de Cristina de Perelti y Cristina Rodríguez Marciel. Madrid: Trotta, 2008.

MARCELLI, Daniel. « Se regarder les yeux dans les yeux: un privilège des êtres humains? Le carnet Psy 2009/8, n. 139, p. 25-33. <https://www.cairn.info/revue-le-carnet-psy-2009-8-page25.htm? contenu=resume $>$.

PARNET, Claire; DELEUZE, Gilles. Dialogues. Paris: Champs, 1977.

SAUVAGNARGUES, Anne. Del animal al arte. Traducción de Irene Agoff. Buenos Aires: Amorrortu, 2006.

SIMONDON, Gilbert. La individuación a la luz de las nociones de forma y de información. Traducción de Pablo Ires. Buenos Aires: Cactus, 2015.

UEXKÜLL, Jacob von. Andanzas por los mundos circundantes de los animales y los hombres. Traducción de Marcos Guntin. Buenos Aires: Cactus, 2016.

YELIN, Julieta. El animal biográfico. $452^{\circ} \mathrm{F}$, n. 17, 2017, p. 36-46.

ZOURABICHVILLI, François. La littéralité et autres essais sur l'art. Paris: PUF, 2011. 